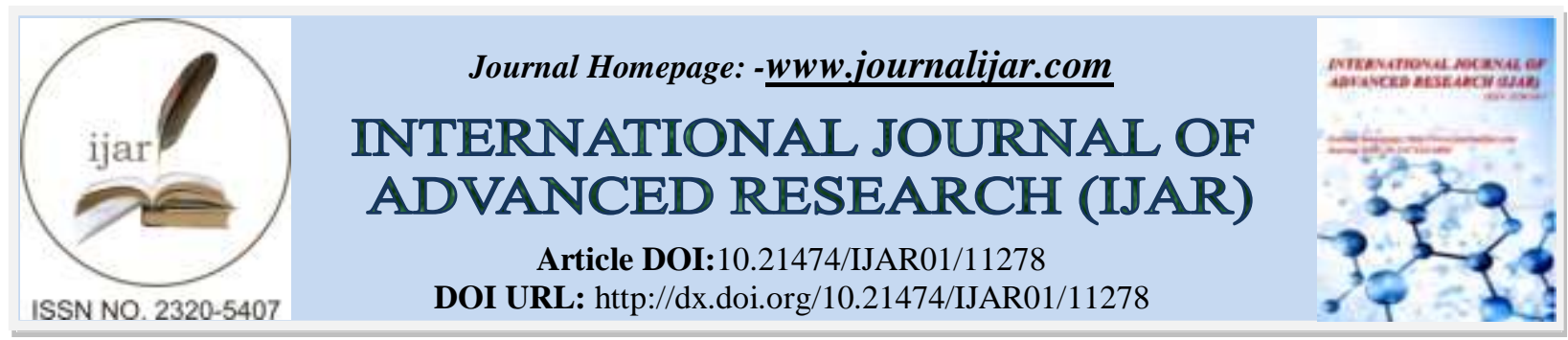

RESEARCH ARTICLE

\title{
A DESCRIPTIVE STUDY TO ASSESS THE RELATIONSHIP BETWEEN QUALITY OF SLEEP AND ACADEMIC PERFORMANCE AMONG NURSING STUDENTS OF COLLEGE OF NURSING
}

\author{
Clinical Instructor, KGMU College of Nursing, Lucknow, U.P.
}

\section{Manuscript Info (......................... \\ Manuscript History \\ Received: 05 May 2020 \\ Final Accepted: 10 June 2020 \\ Published: July 2020 \\ Key words:- \\ Quality of Sleep, Academic \\ Performance, Nursing Students}

\begin{abstract}
A descriptive study was undertaken to assess the Relationship between Quality of Sleep and Academic Performance among Nursing Students in selected College of Nursing, Ludhiana, Punjab. The objectives of the study were to assess the quality of sleep among nursing students, to identify academic performance of nursing students, to assess the relationship between quality of sleep and academic performance, to find out the relationship of quality of sleep and academic performance with selected variables like age, gender, type of course, type of family, residence, academic year, duration of sleep, use of technology, attendance (Clinical \& Theory), Day nap. Quantitative Research Approach and non-experimental descriptive research design was used to accomplish the stated objectives.The conceptual framework was based on King's Conceptual System of Goal Attainment Theory (1981). Data was collected with the help of standardised tool named Pittsburgh Sleep Quality Index (PSQI) which was found reliable $(\mathrm{r}=0.76) .105$ Subjects were chosen by simple random sampling technique. The data collected was analysed using descriptive and inferential statistics. The study revealed that nursing students had good quality of sleep and good academic performance whereas there was no significant relationship between quality of sleep and academic performance. Demographic variables i.e. sleep duration had a significant impact on quality of sleep whereas gender, academic year, attendance and day nap had a significant impact on the academic performance of nursing students. Based on findings of the study guidelines were prepared on quality of sleep \& distributed among nursing students.
\end{abstract}

Copy Right, IJAR, 2020,. All rights reserved.

\section{Introduction:-}

Sleep is a vital physiological process. Its quality is severely related to mental and physical health and other health related criteria. The sleeping and awakening patterns in people varies according to age, type of job, physiological and mental characteristics, existence of mental diseases and some physical diseases (Giri P, Baviskar M, Phalke D, $2013)^{1}$ 
A sleep deprived individual is prone for lacking concentration, being unpleasant and irritable to his co-workers and even makes gross errors in his activities. It also has a long-term effect on his body systems like the brain and the heart. (Gomes, Ana Allen, Tavares, Azevedo, Maria Helena2002) ${ }^{2}$

Research has indicated that emerging college students are at risk for engaging in unhealthy sleep practices. Insufficient sleep and daytime sleepiness have been found to be the highest ranking sleep problem within this population is a concern for today's emerging adults, as sleep deprivation and poor sleep quality have been found to be associated with lowered cognitive performance and decreased physical and psychological well-being. (Wingard DL, Berkman LF) ${ }^{3}$

\section{Need of the study:}

Sleep complaints are common conditions that can overcome. However, worldwide, sleep habit investigators are debating as to how much sleep per night a healthy creature should have. In addition, because of the steady rise in work needs, sleep insufficiency has become a global phenomenon. It has been shown that young adults need an average Total Sleep Time (TST) of 7.5 hours on weeknights and a bit more, that is, 8.5 hours during weekend nights. Accordingly, life constraints affect those students, who are dealing with curative sciences, making them experience irregular sleep habits compared to individual sleep needs (Yousef A. Taher, Awatef M. Samud, Aya H. Ratimy and, Areeje M. Seabe, 2010) ${ }^{4}$.

Earlier studies in Europe and America showed pitiable sleep quality of young college students, which affect their academic growth. Sleep is an important aspect of maintenance the body circadian rhythm. Inadequate sleep contributes to heart disease, diabetes, depression, falls, accidents, impaired cognition and poor quality of life. The habit of sleeping late and sleeping less is more among nursing students due to the increased academic demands leading to effects on their health. Thus, the researcher during the study period experiment that good sleep is important for good academic performance and sleep do have influences on academic performance that why researcher wants to identify the quality of sleep among nursing students in Christian Medical College \& Hospital and to assess the relationship between quality of sleep and academic performance. This study may be benefit the students by allowing them to understand relationship between quality of sleep and academic performance.

\section{Research problem:}

A descriptive study to assess the relationship between quality of sleep and academic performance among nursing students of College of Nursing, Christian Medical College \& Hospital, Ludhiana, Punjab:

\section{Objectives:-}

1. To assess the quality of sleep among nursing students.

2. To identify academic performance of nursing students.

3. To assess the relationship between quality of sleep and academic performance.

4. To find out the relationship of quality of sleep and academic performance with related variables like age, gender, type of course, type of family, residence, academic year, duration of sleep, use of technology, attendance (Clinical \& Theory), Day nap

5. To prepare guidelines on quality of sleep.

\section{Research Methodology:-}

Research approach:

Quantitative (non- experimental) research approach

\section{Research design: \\ Descriptive design}

Setting of the study:

College of Nursing, Christian Medical College and Hospital, Ludhiana, Punjab.

Sampling technique:

Simple Random Sampling Technique 


\section{Sampling size:}

105 Nursing students

\section{Description of the tool:}

A standardised tool was selected i.e. Pittsburgh Sleep Quality Index (PSQI). To use this tool prior written permission was obtained from author.

Tool consisted of three parts

\section{Part I: Socio-demographic variables}

This part consisted of items for obtaining personal information from nursing students i.e. age, gender, type of course, type of family, residence, academic year, duration of sleep, use of technology, mobile use, internet use, TV use, use of technology, attendance (clinical \& theory), day nap etc.

\section{Part II: Pittsburgh Sleep Quality Index (PSQI)}

Pittsburgh Sleep Quality Index (PSQI) is an effective instrument used to measure "poor" from "good" sleep by measuring seven domains: subjective sleep quality, sleep latency, sleep duration, habitual sleep efficiency, sleep disturbances, use of sleep medication, and daytime dysfunction over the last month. The client self-rates each of these seven areas of sleep. Scoring of the answers is based on a 0 to 3 scale, whereby 3 reacts the negative extreme on the Likert Scale (Buysse DJ, 1989) 5

\section{Part III: Academic Performance}

Percentage of marks in university exam (last year)

\section{Reliability of the tool:}

Reliability was computed and calculated using Karl Pearson's coefficient of correlation and spearman's Brown Prophecy formula. The reliability of the tool was 0.768 . Hence, the tool was reliable.

\section{Results:-}

The analysis was done using descriptive and inferential statistics.

Finding related to sample characteristics:

Majority of the nursing students were in age group of 18-22 years and they were female students and from BSc $(\mathrm{N})$, maximum subjects were from 3rd year. Maximum students belong to nuclear family and majority were hostellers. Maximum students have sleep duration of 7-9 hours, watch TV 1-2 hours, internet use $>3$ hours, mobile use $>3$ hours, total technology use $<6$ hours, maximum take day nap and majority have $>90 \%$ attendance.(Table 1 )

Findings related to assessment of Quality of Sleep among Nursing Students:

According to quality of sleep majority of Nursing Students (67.62\%) were having good Quality of Sleep and 32.38\% had poor Quality of Sleep (Fig. 1)

\section{Findings related to assessment of Academic Performance of Nursing Students:}

According to levels of academic performance majority of nursing students $(57.14 \%)$ were having good academic performance, followed by below average (35.83\%). $4.76 \%$ had excellent and $1.90 \%$ had average Academic Performance. (Fig. 2)

Findings related to the relationship between Quality of Sleep and Academic Performance: There is no relation between quality of sleep and academic performance (Table 2)

Findings related to relationship between Quality of Sleep with Selected Variables:

Mean quality of sleep score was high among students with sleep duration 4-6 hours (6.40) followed by $>9$ hours (5.22) followed by 7-9 hours (5.19). Sleep duration had significant impact on quality of sleep. (Fig. 3)

\section{Findings related to relationship between Academic Performance with Selected Variables:}

1. Mean academic performance score was high among female students (49.32) as compared to male (24.86). Gender had significant impact on academic performance. (Table 3)

2. Mean academic performance score was high among hosteller (48.95) as compared to day scholar (37.25). 
Residence had significant impact on academic performance. (Fig. 4)

3. Mean academic performance score was high among fourth year (61) followed by third year (37.50) followed by second year nursing students (36.50). Academic Year had significant impact on academic performance. (Table 4)

4. Mean academic performance score was high among students who had 80-89\% attendance (53.39) followed by $>90 \%$ (47.99). Attendance had significant impact on academic performance. (Fig. 5)

5. Mean academic performance score was high among students taking day nap (50.47) as compared to not taking day nap (35.64). Day nap had significant impact on academic performance. (Fig. 6)

Section - I: Socio demographic variables of sample

Table 1:- Frequency and Percentage Distribution of Nursing Students according to Selected Variables N=105

\begin{tabular}{|c|c|c|}
\hline \multirow[b]{2}{*}{ Sample Characteristics } & \multicolumn{2}{|c|}{ Nursing Students } \\
\hline & (f) & $(\%)$ \\
\hline Age (years) & & \\
\hline $18-22$ & 97 & 92.38 \\
\hline $23-27$ & 8 & 7.62 \\
\hline $28-32$ & 0 & 0 \\
\hline$>32$ & 0 & 0 \\
\hline Gender & & \\
\hline Male & 26 & 24.76 \\
\hline Female & 79 & 75.24 \\
\hline Type of Course & & \\
\hline GNM & 25 & 23.81 \\
\hline B. Sc. (N) & 80 & 76.19 \\
\hline Type of Family & & \\
\hline Nuclear & 87 & 82.86 \\
\hline Joint & 18 & 17.14 \\
\hline Residence & & \\
\hline Hosteller & 54 & 51.43 \\
\hline Day Scholar & 51 & 48.57 \\
\hline Academic Year & & \\
\hline Second Year & 29 & 27.62 \\
\hline Third Year & 49 & 46.67 \\
\hline Fourth Year & 27 & 25.71 \\
\hline Sleep Duration (in night) & & \\
\hline 4-6 hours & 40 & 38.10 \\
\hline 7-9 hours & 42 & 40.00 \\
\hline$>9$ hours & 23 & 21.90 \\
\hline TV Use & & \\
\hline 1-2 hour & 89 & 84.76 \\
\hline$>3$ hour & 16 & 15.24 \\
\hline Internet Use & & \\
\hline $1-2$ hour & 48 & 45.71 \\
\hline$>3$ hour & 57 & 54.29 \\
\hline
\end{tabular}




\begin{tabular}{|l|l|l|}
\hline \multicolumn{2}{|l|}{} & Nursing Students \\
\hline Sample Characteristics & (f) & $(\%)$ \\
\hline Mobile Use & & \\
$1-2$ hour & 35 & 33.33 \\
$>3$ hour & 70 & 66.67 \\
& & \\
Total Technology used & 62 & 59.05 \\
$<6$ hour & 43 & 40.95 \\
$>6$ hour & & \\
& & \\
Attendance (clinical \& theory) & 40 & 38.10 \\
$\geq 90 \%$ & 31 & 29.52 \\
$80-89 \%$ & 15 & 14.29 \\
$70-79 \%$ & 19 & \\
$\leq 69 \%$ & & \\
& 54 & 51.43 \\
Day Nap & 51 & 48.57 \\
yes & 54 & \\
no & & \\
\hline
\end{tabular}

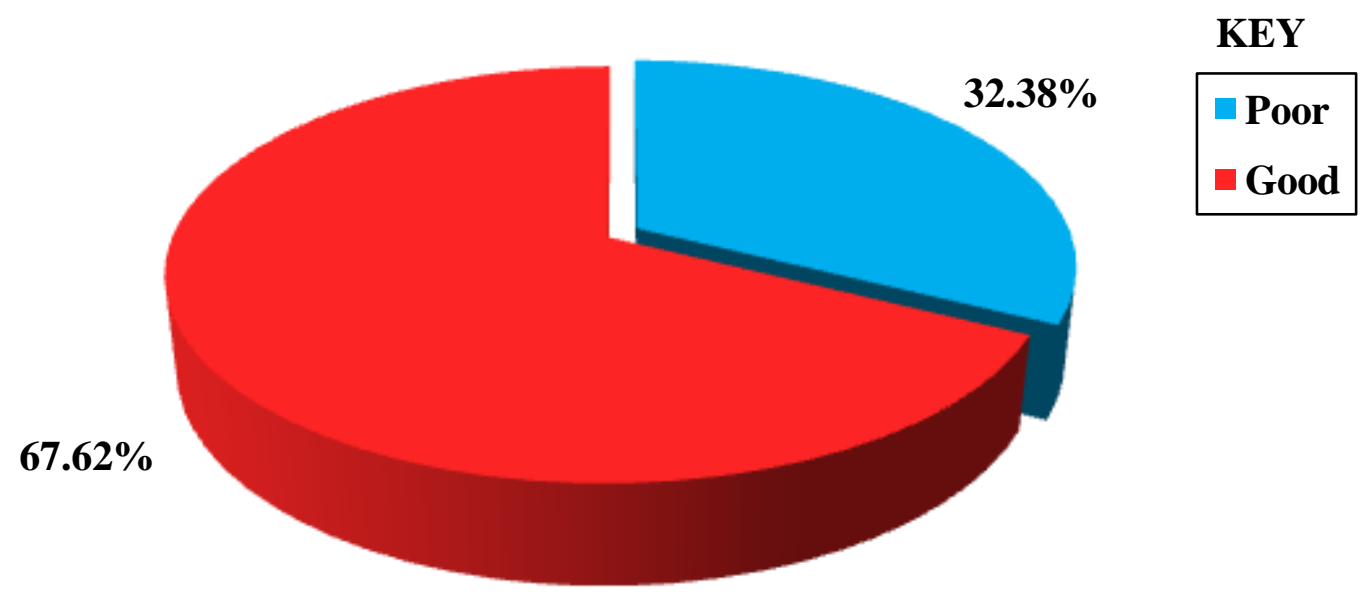

\section{QUALITY OF SLEEP}

Fig. 1:- Percentage Distribution of Nursing Students according to Quality of Sleep. 


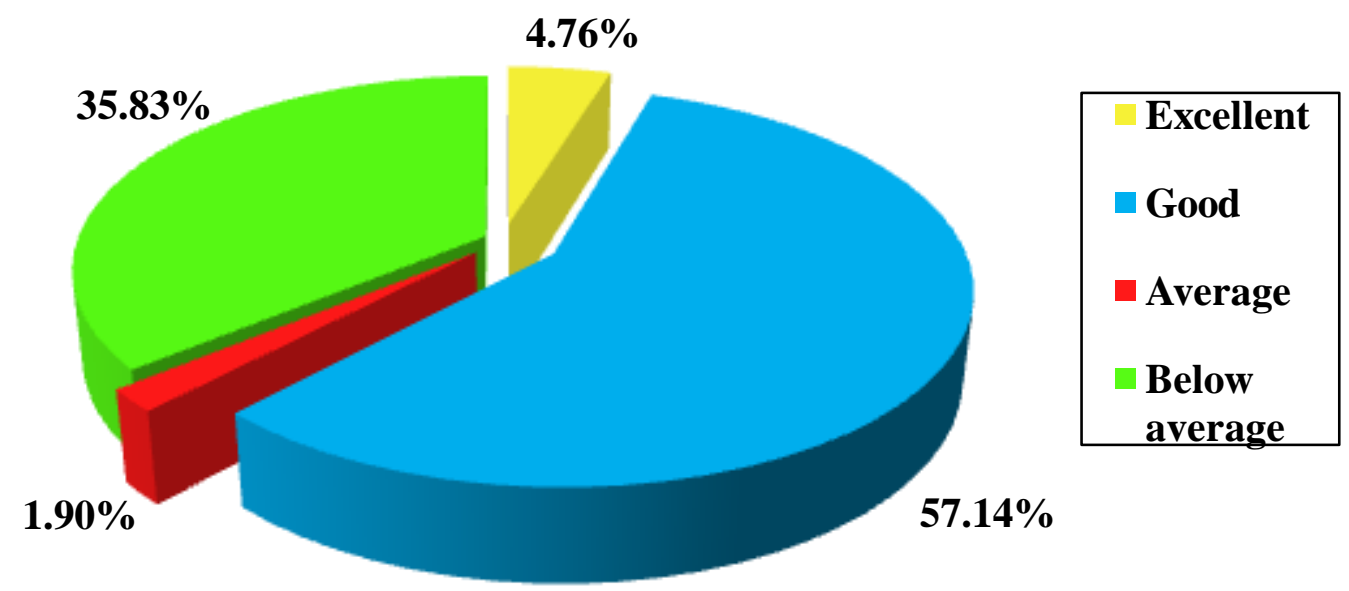

\section{ACADEMIC PERFORMANCE}

Fig. 2:- Percentage Distribution of Nursing Students according to Academic Performance.

Table 2:- Mean, standard Deviation and Co-relation between Quality of Sleep \& Academic Performance of Nursing Students N=105.

\begin{tabular}{|l|l|l|l|}
\hline \multirow{2}{*}{ Co-relation } & \multicolumn{3}{|c|}{ Score } \\
\cline { 2 - 4 } & Mean & SD & "r" \\
\hline $\begin{array}{l}\text { Quality of Sleep } \\
\text { Academic Performance }\end{array}$ & 5.66 & 2.40 & -0.11 \\
\hline
\end{tabular}

Maximum Quality of Sleep Score $=21$

Minimum Quality of Sleep Score $=0$
Maximum Academic Performance Score $=100$ Minimum Academic Performance Score $=0$

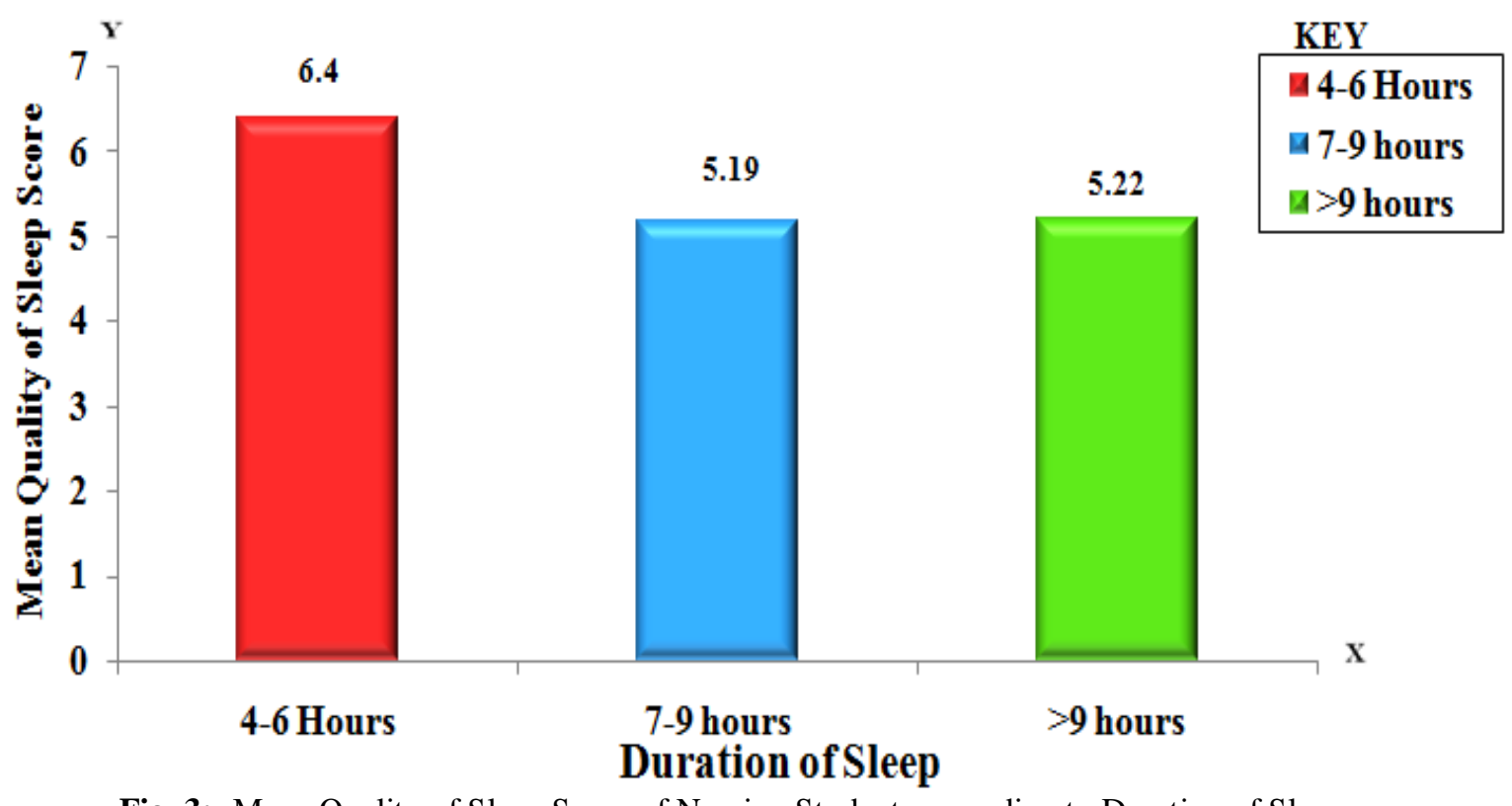

Fig. 3:- Mean Quality of Sleep Score of Nursing Students according to Duration of Sleep. 
Table 3:- Mean, Standard Deviation and t test of Quality of Sleep Score and Academic Performance Score of Nursing Students according to Gender $\mathbf{N = 1 0 5}$.

\begin{tabular}{|l|l|l|l|l|l|l|l|}
\hline & \multicolumn{3}{|l|}{ Nursing Students } & \multicolumn{3}{l|}{$\begin{array}{l}\text { Quality of Sleep Score } \\
\text { Score }\end{array}$} \\
\hline Gender & $\mathbf{n}$ & Mean & SD & 't' & Mean & SD & 't' \\
\hline Male & 26 & 5.15 & 2.03 & & 24.86 & 32.19 & \multirow{2}{*}{$3.45^{* *}$} \\
\hline Female & 79 & 5.82 & 2.50 & & $4.24^{\mathrm{NS}}$ & & \\
\hline
\end{tabular}

Maximum Quality of Sleep Score $=21 \quad$ Maximum Academic Performance Score $=100$

Minimum Quality of Sleep Score $=0 \quad$ Minimum Academic Performance Score $=0$

NS = Non-significant

${ }^{* * *}$ Significant $\mathbf{p}<$ at 0.01 level

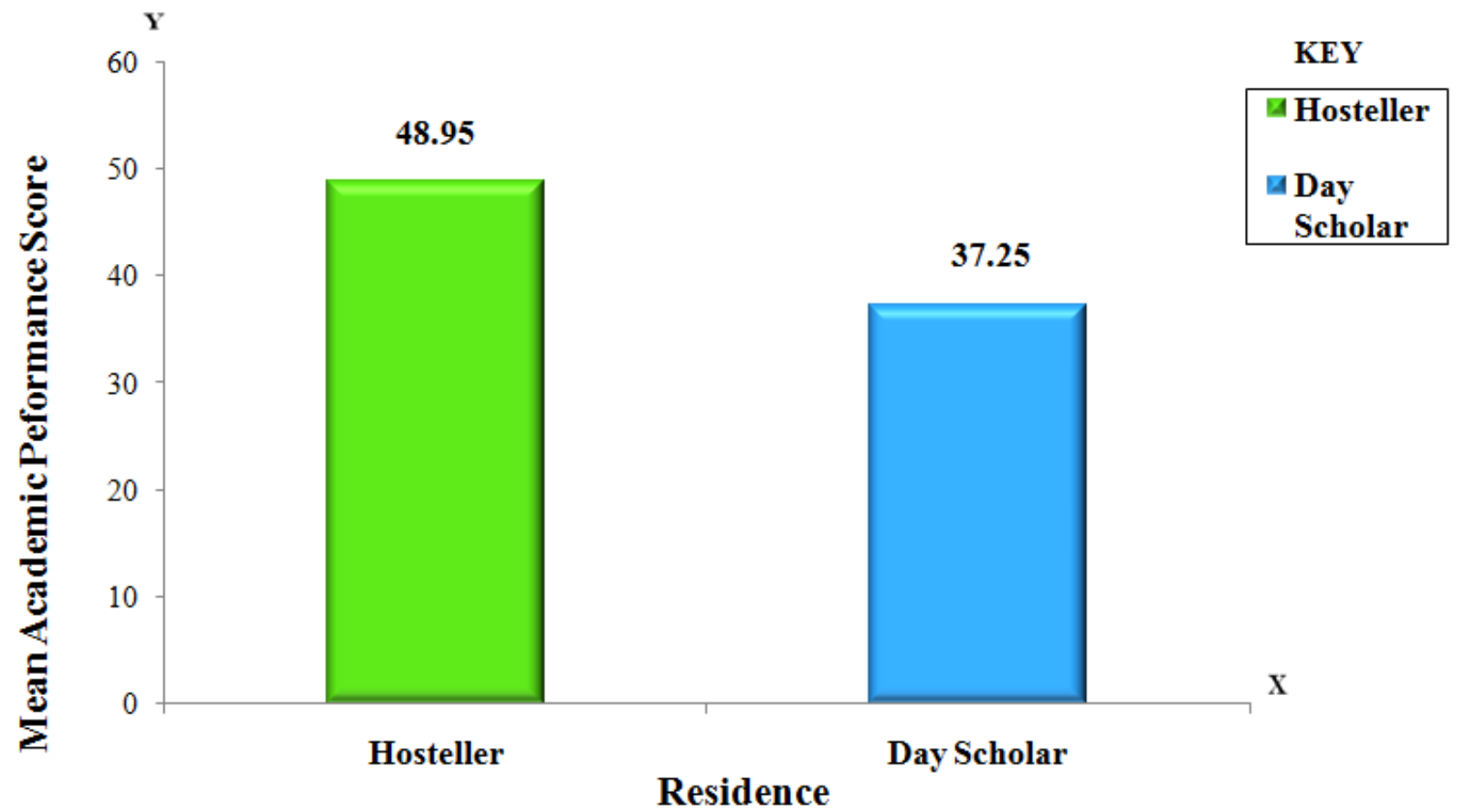

Fig. 4: Mean Academic Performance Score of Nursing Students according to Residence

Table 4:- Mean, Standard Deviation and Analysis of Variance of Quality of Sleep Score and Academic Performance Score of Nursing Students according to Academic Year $\mathbf{N}=\mathbf{1 0 5}$.

\begin{tabular}{|l|l|l|l|l|l|l|l|}
\hline & \multicolumn{7}{|l|}{ Nursing Students } \\
\hline & \multicolumn{3}{|l|}{ Quality of Sleep score } & & Academic Performance score & \\
\hline Academic Year & n & Mean & SD & & Mean & SD & \\
\hline Second & 29 & 6.41 & 2.13 & & 36.50 & 33.58 & \\
\hline Third & 49 & 5.47 & 2.55 & & 37.50 & 34.42 & \\
\hline Fourth/Intern & 27 & 5.19 & 2.29 & & 61 & 22.66 & \\
\hline $\begin{array}{l}\text { Source of } \\
\text { Variation }\end{array}$ & df & $\begin{array}{l}\text { Sum of } \\
\text { Squares }\end{array}$ & MS & F & Sum of Squares & MS & F \\
\hline Between groups & 2 & 24.345 & 12.17 & $2.16^{\text {NS }}$ & 11446.44 & 5723.22 & \multirow{2}{*}{$5.73^{* *}$} \\
\hline Within groups & 102 & 573.313 & 5.64 & & 101782.48 & 997.66 & \\
\hline
\end{tabular}




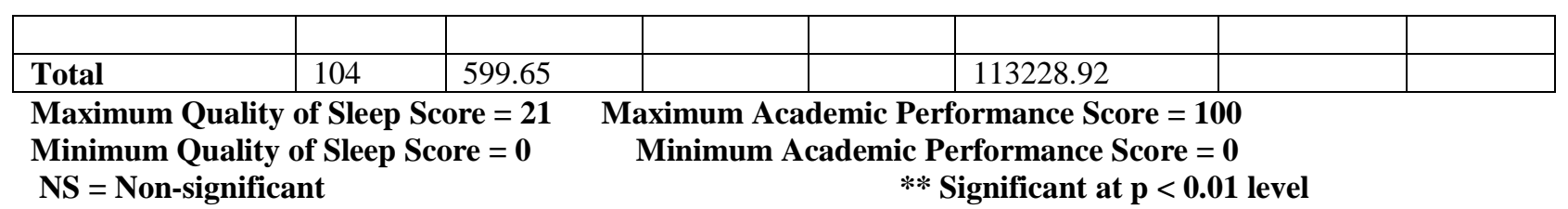

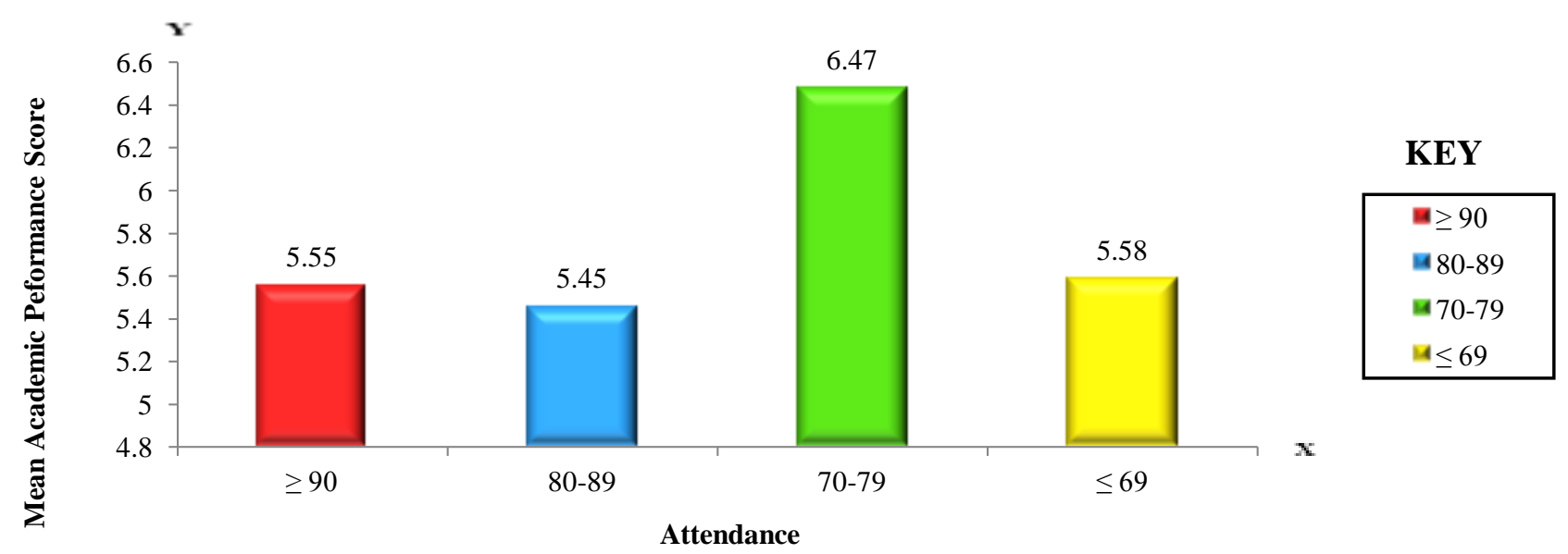

Fig. 5:- Mean Academic Performance Score of Nursing Students according to Academic Year.

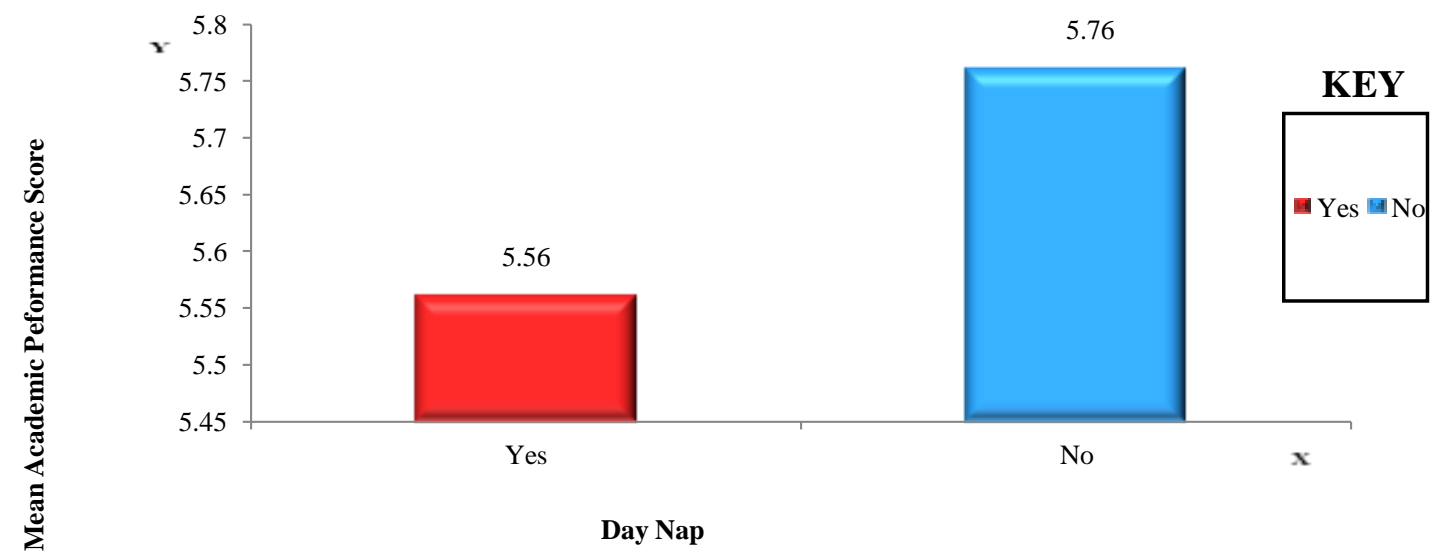

Fig. 6:- Mean Academic Performance Score of Nursing Students according to Day Nap.

\section{Conclusion:-}

Sleep is an essential element for adolescent mental and physical growth and development. The study concluded thatNursing Students had good Quality of Sleep and good Academic Performance whereas there was no significant relationship between Quality of Sleep and Academic Performance. Demographic variables i.e. Sleep Duration had a significant impact on Quality of Sleep whereas Gender, Academic Year, Day Nap and Attendance had a significant impact on the Academic Performance of Nursing Students

\section{Discussion:-}

The analysis of the data revealed that majority of nursing students (67.62\%) had good quality of sleep and 32.38\% had poor quality of sleep. These finding were supported by Entsarkamel M EI Desouky et al (2015) ${ }^{\mathbf{6}}$ who found that nursing students had good quality of sleep as well as good academic performance.

According to another objective i.e. to assess the relationship between quality of sleep and academic performance,in the present study the finding revealed that there was no relationship between quality of sleep and academic performance. This was supported by Aabid Ali, Muhammad Bilal Majeed, KanwalSaba, Amanda Bodenarain, 
Mulazim Hussain Bukhari $(2013)^{7}$ who found that there is no significance among two variable sleep pattern and academic performance of medical students.Study done by Raphael, Gilbert odille $(2014)^{8}$ was contradictory to present study which shows that there was positive correlation between sleep quality and academic performance. Study results AK. Abrbag, M Dresler, S. Nicdrmaier (2012) ${ }^{9}$ revealed that poor sleep quality may negative impact on test performance, these results are also contradictory to present research study .

Present study revealed that the maximum mean academic performance score was maximum (49.32) as compared to males (24.86). But the difference in mean academic performance score was found statistically non-significant. This was supported by S.H. Cheng et al $(2012)^{10}$ who states thatfemale have good academic performance than male students. Nursing students who had $80-90 \%$ attendance had maximum mean academic performance score as compared to those with attendance 70-79\%. The findings are supported by Ella R.E, Akpabio\& Samson Akpan $(2015)^{11}$ study affirms the fact that class attendance influence academic performance of students. So, attendance influenced academic performance of nursing students.

\section{Acknowledgement:-}

With profound gratitude, I would like to express my deep appreciation to my esteemed supervisor Prof. (Mrs.) Ponnamma R. Singh, Professor \& Principal, College of Nursing, Christian Medical College and Hospital, Ludhiana for her valuable time, suggestions and great personal interest taken in each step and also for granting permission and providing all needed support to conduct the study. I would like to express my deep gratitude to my co- supervisor $\mathrm{Dr}$ Usha Singh, Professor, College of Nursing, for her guidance, encouragement, understanding and consistent support that was extended in every phase of work.I am deeply grateful tomy family and friends for encouraging, helping, inspiring me always to complete my work and for being a great support.

\section{References:-}

1. Giri P, Baviskar M, Phalke D. Study of sleep habits and sleep problems among medical students of pravara institute of medical sciences, Western Maharashtra, India. Annals of Medical and Health Sciences Research. 2013; 3(1):51-4.

2. Gomes, Ana Allen, Tavares, Azevedo, Maria Helena. Sleep- wake patterns and academic performance in university students. Paper presented at the European Conference on Educational Research, University of Lisbon; 2002.

3. Wingard DL, Berkman LF., Mortality risk associated with sleeping patterns among adults, Sleep. 1983; 6 (2):102-7.

4. Yousef A. Taher et al. Sleep complaints and daytime sleepiness among pharmaceutical students, Libyan Journal Medicine 2012; 7: 18930.

5. Buysse DJ, Reynolds CF 3rd, Monk TH, Berman SR, Kupfer DJ. The Pittsburgh Sleep Quality Index: a new instrument for psychiatric practice and research. Psychiatry Res. 1989; 28:193-213

6. Entsarkamel M. El Desouky, josephinAtef A. Lawend, HowidaAbuEllife M. Awed. Relationship between quality of sleep and academic performance among female nursing students. International journal of nursing didactics, 5:9 sept (2015)

7. Aabid Ali1, Muhammad Bilal Majeed, KanwalSaba, Amanda Bodenarain, Mulazim Hussain Bukhari, Effects of different sleeping patterns on academic performance in medical school students. 2013; 5(11)

8. Raphael M G, Gilbert O A, Lucy K, Joyline M. The effect of sleep quality on performance of students in public university, Kenya. International Journal of Educational Research and Technology. June 2014;5 (2):68-73.

9. Aherberg K. et al. The interaction between sleep quality and academic performance, Journal of psychiatric Research; 46 (2012) 1618-22.

10. S.H. Cheng et al. / A study on the sleep quality of incoming university students Psychiatry Research 197 (2012) 270-274 271

11. Ella R.E, Akpabio \& Samson Akpan, International Journal of Humanities Social Sciences and Education (IJHSSE). November 2015; 2 (11): 108-114. 